\title{
Mechanical and Electrical Characterization of Self-sensing Carbon Black ECC
}

\author{
Vincent W. J. Lin ${ }^{\mathrm{a}}$, Mo Li ${ }^{\mathrm{a}}$, Jerome P. Lynch ${ }^{\mathrm{a}, \mathrm{b}}$, Victor C. Li* ${ }^{\mathrm{a}}$ \\ ${ }^{a}$ Dept. of Civil and Environmental Engineering, University of Michigan, Ann Arbor, Michigan; \\ ${ }^{\mathrm{b}}$ Dept. of Electrical Eng. and Computer Science, University of Michigan, Ann Arbor, Michigan
}

\begin{abstract}
In this paper, the development of a new variation of Engineered Cementitious Composite (ECC) that aims to combine tensile ductility with self-sensing ability is described. ECC is a new type of high-performance fiber reinforced cementitious composite that exhibits strain-hardening under applied tensile load while resisting fracture localization. The self-sensing ability is achieved by incorporating a small dosage of carbon black (CB) into the ECC system (hereafter known as CB-ECC) to enhance its piezoresistive behavior while maintaining its tensile strain-hardening behavior. The tensile stress-strain response of CB-ECC is studied with an emphasis on its tensile stress and strain capacity, as well as its cracking pattern. In addition, the piezoresistive behavior of CB-ECC under uniaxial tension is investigated. Specifically, the effect of carbon black content on the electrical properties of ECC including the sensitivity of changes in its bulk conductivity under applied tensile strain are explored in detail.
\end{abstract}

Keywords: Engineered cementitious composite (ECC), carbon black, piezoresistivity, structural monitoring, smart structures

\section{INTRODUCTION}

In the last two decades, significant advancements in concrete technology have been achieved in the civil engineering field. Cement-based materials with higher compressive strength ${ }^{1}$, tensile strength, ductility and toughness ${ }^{2-5}$ have been developed. For example, Engineered Cementitious Composite (ECC) is a cement-based material reinforced with a relatively low fiber volume fraction $(<2 \%)$ to exhibit pronounced strain-hardening with multiple micro-cracking behavior when subjected to uniaxial tension ${ }^{2-4}$. The development of ECC is rooted in fracture mechanics theory with the microstructure of the material tailored to achieve extraordinary toughness and ductility. Besides advancements in the mechanical properties of cement-based materials, numerous studies ${ }^{6-22}$ have also been conducted to develop self-sensing cement-based materials for various structural monitoring applications. Potential applications of self-sensing cementbased materials include their use as strain/stress sensors, damage sensor and traffic load monitoring sensor ${ }^{6-10}$. Chen and Chung ${ }^{11}$ were among the first to develop self-sensing cement-based materials. Through the incorporation of a small volume fraction $(0.2$ to $0.4 \%)$ of short-discontinuous carbon fibers to conventional mortar (hereafter known as carbon fiber reinforced mortar or CFRM), significant changes were observed in the composite's electrical resistivity responding to compressive loadings, rendering CFRM a self-sensing material. However, when tested under cyclic compression loading, changes in CFRM's resistivity were found to increase irreversibly with increasing compression up to a third of its ultimate compressive strength in the first cycle due to the generation of irreversible flaws. Nonetheless, reversible changes in resistivity were observed upon subsequent loading and unloading cycles due to the closing and opening of cracks, respectively. Many studies that followed focused on the improvement of cement-based material's electrical conductivity and reversibility in resistivity change upon loading and unloading through: (i) the use of dispersants to improve the distribution of the conductive fibers ${ }^{12}$; (ii) the treatment of fiber-matrix interfacial properties ${ }^{13}$; and, (iii) the use of different types (or a combination) of conductive fibers and fillers ${ }^{6,14-15}$. Numerous investigations had also been undertaken to understand the piezoresistive behavior of self-sensing cement-based materials when subjected to different types of load scenarios such as compression, tension and flexure ${ }^{16-19}$, and environmental conditions such as temperature, humidity/water content and curing conditions ${ }^{6,20-22}$.

*vcli@umich.edu; phone 1734 764-3368; fax 1734 764-4292; http://ace-mrl.engin.umich.edu

Nondestructive Characterization for Composite Materials, Aerospace Engineering, Civil Infrastructure, and Homeland Security 2011, edited by H. Felix Wu, Proc. of SPIE Vol. 7983, 798316 - @ 2011 SPIE

CCC code: $0277-786 X / 11 / \$ 18 \cdot$ doi: $10.1117 / 12.880178$

Proc. of SPIE Vol. $7983798316-1$ 
Despite numerous studies carried out on self-sensing cement-based materials, little work has been devoted to the development of self-sensing cement-based materials with superior mechanical properties such as those of ECC. As such, the objective of this study is to develop a self-sensing carbon black ECC (hereafter known as CB-ECC) that possesses both excellent mechanical properties for structural applications and piezoresistive behavior for structural monitoring applications. Among the parameters of interest in understanding the uniaxial tensile and piezoresistive behavior of CBECC include: (i) the tensile stress capacity; (ii) ductility; (iii) cracking behavior; and, (iv) gage factor. In this study, these four parameters are studied when different carbon black content is incorporated into the ECC system.

\section{EXPERIMENTAL PROGRAM}

A total of 7 tensile coupon specimens (304.8 $\mathrm{mm}$ long by $76.7 \mathrm{~mm}$ wide by $12.7 \mathrm{~mm}$ thick) were fabricated and tested. These specimens comprised one conventional ECC specimen serving as control and six CB-ECC specimens of different carbon black content of $0.25 \%$ (two specimens), $0.5 \%$ (two specimens) and $1.0 \%$ (two specimens) by weight ratio to total cementitious content (Cement + Fly Ash). All the specimens were reinforced with $2.0 \%$ of polyvinyl alcohol (PVA) fibers by volume fraction. The mix compositions of each type of specimen are summarized in Table 1 . The conventional ECC specimen is denoted as M45 ECC while the CB-ECC specimens are denoted by its acronym CB-ECC followed by a number that indicates its carbon black content (percentage by weight to total cementitious content).

\subsection{Materials}

The dry component materials used in this study are Type 1 Portland cement, F-110 foundry silica sand and Class F normal fly ash. The carbon black particles used are from Cabot Corporation having a trade name of Vulcan XC72R. These carbon black particles have average size of $30 \mathrm{~nm}$ and bulk resistivity of approximately $10^{-1} \mathrm{Ohm} . \mathrm{cm}$. The superplasticizer used is a high-range water reducer having the trade name of ADVA Cast 530 from W. R. Grace \& Co. The PVA fibers (PVA-REC 15) are $12 \mathrm{~mm}$ in length and $39 \mu \mathrm{m}$ in diameter. The nominal tensile strength and density of the fibers are $1600 \mathrm{MPa}$ and $1300 \mathrm{~kg} / \mathrm{m}^{3}$, respectively. These PVA fibers are surface-coated by oil $(1.2 \%$ by weight $)$ to intentionally reduce the fiber/matrix interfacial bond strength so as to achieve the desired fiber pull-out mechanism for composite strain-hardening behavior ${ }^{2}$.

\subsection{Specimen preparation}

The mixing process of the M45 ECC and CB-ECC specimens was as follows. Using a Hobart mixer, cement, fine silica sand, fly ash and carbon black particles (if any) were first dry-mixed thoroughly for approximately one minute. Water and super-plasticizer were then poured into the Hobart mixer and mixed for three minutes until a relatively homogeneous cement slurry was formed. PVA fibers were then slowly added into the mix and the mixing continued for two to three minutes to ensure uniform dispersion of the PVA fibers in the mix. The mix was then poured into molds and allowed to set. The specimens were kept in the molds covered with plastic sheets for 24 hours before they were de-molded and then moist-cured in a plastic bag for an additional six days until the age of 7 days. After 7 days, the specimens were taken out of the plastic bag and cured within normal indoor air conditions. The specimens were tested at the approximate age of 1 year.

Table 1. Summary of mix compositions by weight ratio to cement content.

\begin{tabular}{|c|c|c|c|c|c|c|}
\hline Specimen ID & Cement & Fly Ash & Sand & Carbon Black (\%) & Water & Super-plasticizer \\
\hline M45 ECC & 1.0 & 1.2 & 0.8 & - & 0.60 & 0.012 \\
\hline CB ECC-0.25 & 1.0 & 1.2 & 0.8 & $0.114 \%$ & 0.60 & 0.013 \\
\hline CB ECC-0.5 & 1.0 & 1.2 & 0.8 & $0.227 \%$ & 0.60 & 0.016 \\
\hline CB ECC-1.0 & 1.0 & 1.2 & 0.8 & $0.455 \%$ & 0.60 & 0.022 \\
\hline
\end{tabular}




\subsection{Tensile piezoresistivity testing procedure}

The experimental setup for uniaxial tensile testing of a typical specimen is shown in Figure 1. Both ends of the specimen were secured with mechanical grips which were then attached to an Instron E10000 actuator through the use of hydraulic grips. The mechanical grips allow the specimen to move out-of-plane to prevent any torsion moment that may act on the specimen if it was directly attached to the actuator through the hydraulic grips. The elongation of the specimen was measured using two LVDT displacement transducers (Honeywell Model-S5 Part No. 060-K061-01) placed on opposite sides of the specimen with a gage length of approximately $110 \mathrm{~mm}$. The load was applied using displacement control at a constant rate of $0.05 \mathrm{~mm} / \mathrm{min}$ during the elastic load segment and $0.5 \mathrm{~mm} / \mathrm{min}$ during the inelastic load segment. Data acquisition was carried out through a computer using the Bluehill2 data acquisition software; a sampling rate of 0.1 second was used. One of the two sets of specimens was white-wash painted 24 hours prior to testing to allow better visibility of the evolution of the crack field.

The resistivity of the specimen was measured throughout the loading process using 4-point probe method as shown in Figure 1. A layer of silver conductive paste (PELCO ${ }^{\circledR}$ Conductive Silver 187 from Ted Pella, Inc) was first applied to the specimen before copper conductive tape (from $3 \mathrm{M}^{\mathrm{TM}}$ ) acting as electrodes were attached; the silver paste enhances the conductivity between the electrodes and the specimen. The spacing between the input/output current electrodes and voltage electrodes is $30 \mathrm{~mm}$, while the spacing between the two voltage electrodes is $100 \mathrm{~mm}$. The resistivity measurements were carried out using the Solartron 1260 impedance/gain-phase analyzer, in which the input current was fixed at $100 \mathrm{~Hz}$, while the excitation voltage was set at $100 \mathrm{mV}$. The auto-integration mode was off and the measurement integration time was a period of one second. Resistivity measurements were taken using a 2 second interval.
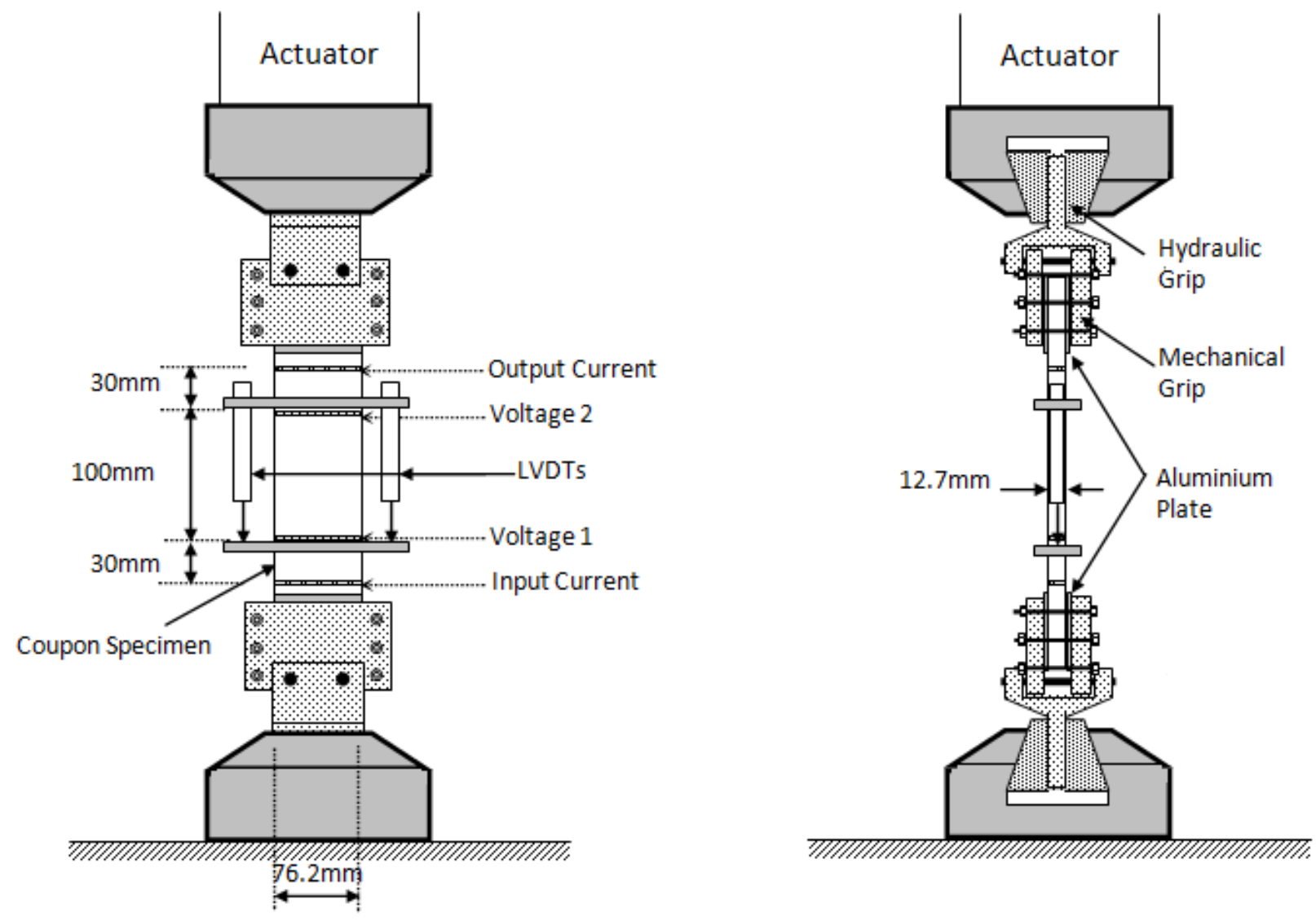

Figure 1. Uniaxial tensile experimental set-up using an Instron E10000 actuator. 


\section{EXPERIMENTAL RESULTS AND DISCUSSION}

\subsection{Tensile stress-strain responses}

The tensile stress-strain response of each specimen is shown in Figure 2. The tensile stress was calculated by dividing the applied load recorded by the actuator load cell over the cross-sectional area of the specimen. The strain was calculated by taking the average value of the elongation measured by the LVDT displacement transducers divided by the gage length $(\sim 110 \mathrm{~mm})$. Table 2 summarizes the numerical values of the key parameters obtained from the experimental tests. The first crack stress and strain were identified as the value before the first drop in the stress-strain curve which indicates that the first through-crack had occurred ${ }^{23}$. Strain at failure was taken at the value where the specimen failed or at $90 \%$ of the post-ultimate stress when tension-softening was observed. In general, all of the CB-ECC specimens (except one CB-ECC-0.5 specimen) exhibited higher first crack and ultimate tensile strength compared to M45 ECC. It should be noted the CB-ECC- 0.5 specimen that had lower tensile strength and strain capacity failed prematurely outside the LVDT gage length (see Figure 3). Post-experimental observations showed multiple large flaws at the failed crosssectional plane which indicated that the lower tensile strength and strain capacity was due to fabrication problem. The apparently higher first crack and ultimate tensile strength exhibited by all of the other CB-ECC specimens could be attributed to the enhanced matrix tensile strength and the stronger fiber/matrix interfacial bond, resulting from the denser packing of the matrix due to the nano-size carbon black particles. However, given that only one M45 ECC was tested in this set-up, further testing is needed to confirm the above observations in a more statistically sound manner. All CB-ECC specimens exhibited lower tensile strain capacity compared to M45 ECC. Nonetheless, there was a lack of a consistent trend in the decrease of tensile strain capacity with increased carbon black content. In fact, CB-ECC-1.0 had the highest tensile strain capacity among all of the CB-ECC specimens. Further studies on the effect of carbon black particles on the matrix strength and fiber/matrix interfacial properties should be conducted for better understanding and verification of the aforementioned experimental observations.

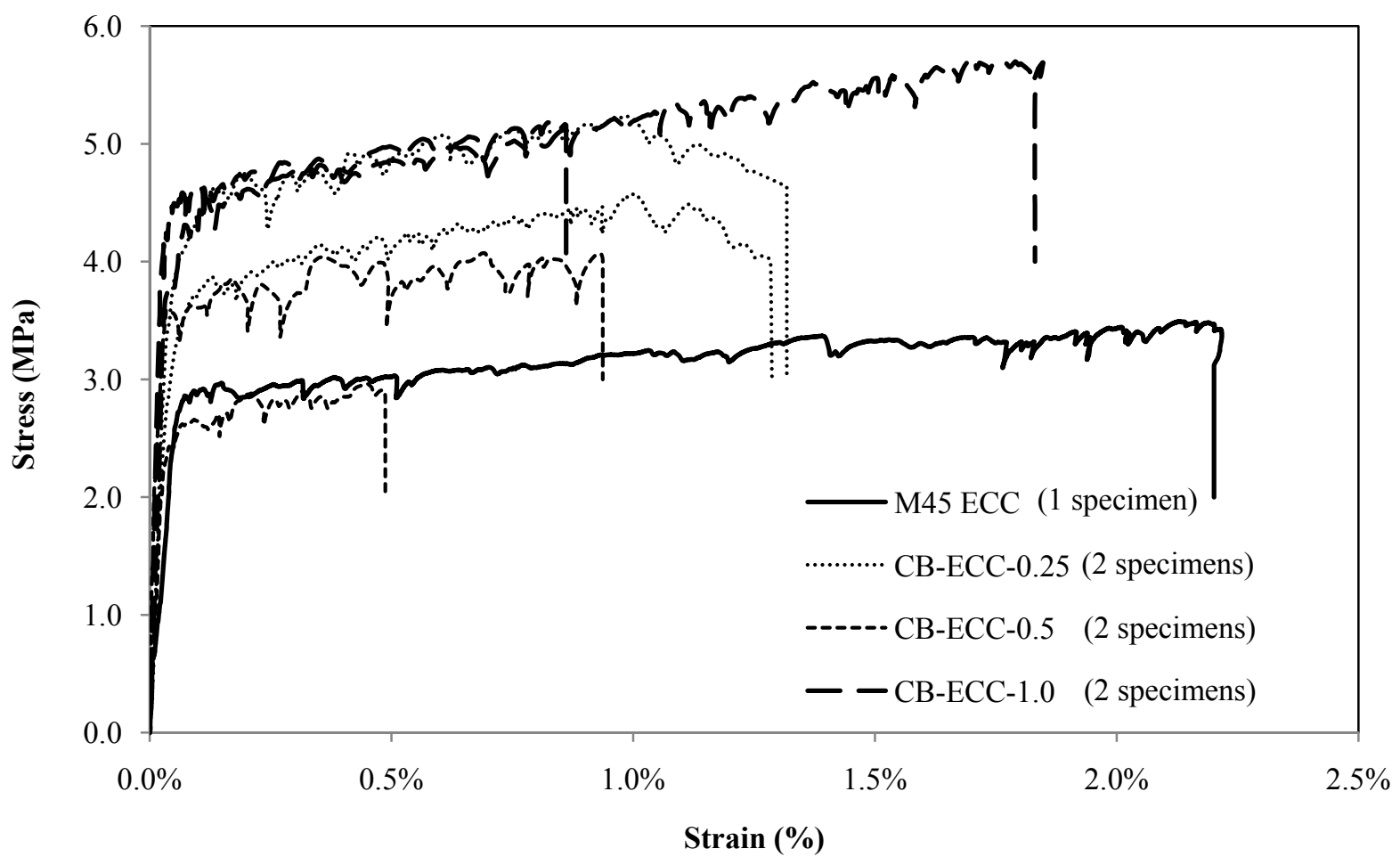

Figure 2. Tensile stress-strain responses of the M45 and CB-ECC specimens. 
Table 2. Summary of key mechanical response parameters of M45 ECC and CB-ECC.

\begin{tabular}{|c|c|c|c|c|c|}
\hline Specimen ID & $\begin{array}{c}\text { First Crack Stress } \\
\text { (MPa) }\end{array}$ & $\begin{array}{c}\text { First Crack Strain } \\
(\%)\end{array}$ & $\begin{array}{c}\text { Ultimate Stress } \\
\text { (MPa) }\end{array}$ & $\begin{array}{c}\text { Strain at Failure } \\
(\%)\end{array}$ & $\begin{array}{l}\text { Remarks about the } \\
\text { Specimen Failure }\end{array}$ \\
\hline M45 ECC & 2.856 & 0.076 & 3.493 & 2.201 & $\begin{array}{l}\text { Failed between current } \\
\text { and voltage electrode }\end{array}$ \\
\hline \multirow{2}{*}{ CB-ECC-0.25 } & 4.401 & 0.108 & 5.230 & 1.318 & Failed within gage length \\
\hline & 3.482 & 0.068 & 4.575 & 1.243 & Failed within gage length \\
\hline \multirow{2}{*}{ CB-ECC-0.5 } & 3.589 & 0.036 & 4.072 & 0.937 & $\begin{array}{l}\text { Failed between current } \\
\text { and voltage electrode }\end{array}$ \\
\hline & 2.430 & 0.043 & 2.961 & 0.487 & $\begin{array}{l}\text { Failed between current } \\
\text { and voltage electrode }\end{array}$ \\
\hline \multirow{2}{*}{ CB-ECC-1.0 } & 4.145 & 0.029 & 5.182 & 0.861 & $\begin{array}{l}\text { Failed between current } \\
\text { and voltage electrode }\end{array}$ \\
\hline & 3.871 & 0.043 & 5.734 & 1.831 & $\begin{array}{l}\text { Failed outside the current } \\
\text { electrode }\end{array}$ \\
\hline
\end{tabular}

\subsection{Cracking behavior}

In general, ECC exhibits multiple micro-cracking behavior when subjected to uniaxial tension through its fiber bridging mechanism. Unlike conventional unreinforced cementitious composites that fail after the first crack developed, the fiber reinforcements in ECC bridges the crack and continue to transfer stresses across the crack plane, leading to new crack formation at the next weaker plane. The process repeats itself forming multiple micro-cracks spreading across the specimen until the applied stress exceeds the fiber bridging strength at one crack plane leading to the localization of the crack which eventually fails the specimen ${ }^{24}$. Owing to this fiber bridging mechanism, the tensile stress capacity of ECC is generally higher than conventional cementitious composites and more importantly, the strain capacities of ECC are typically one to two orders of magnitude larger than conventional cementitious composites, hence providing ECC with much higher energy absorption capacity/ dissipation ability.

Figure 3 shows the typical cracking pattern of the M45 ECC and CB-ECC specimens. The micro-cracks were highlighted with pencil to improve its visibility when photographed. Multiple fields of micro-cracking were observed in all CB-ECC specimens, except for CB-ECC- 0.5 which failed prematurely as previously mentioned. However, it should be noted that multiple micro-cracks were observed in all other CB-ECC specimens tested in the first round of testing that did not use white-wash. The average crack width of the M45 ECC and CB-ECC specimens measured after unloading was approximately 50 and $30 \mu \mathrm{m}$, respectively. These observations suggested that the incorporation of carbon black particles into the ECC system reduces its crack width and does not affect its multiple micro-cracking behavior. Nonetheless, a reduction in the tensile strain capacity of CB-ECC was generally observed.

\subsection{Effect of carbon black content on CB-ECC bulk resistivity}

The effect of carbon black content on CB-ECC bulk resistivity is plotted in Figure 4. As expected, the bulk resistivity of CB-ECC decreases as more carbon black particles were added to the ECC system. As a larger amount of carbon black particles were added to the material composition, the inter-particle spacing between the carbon black particles reduced. It is suspected that more linkages were formed to conduct current, thus decreasing its bulk resistivity. From the linear trend of the resistivity versus carbon black content plot, it can also be concluded that the percolation threshold is beyond $1.0 \%$ of carbon black content (by weight to cementitious content). It is also worth mentioning here that lower material bulk resistivity is desired in piezoresistivity measurements as it enhances the signal to noise ratio (background resistivity) which improves the material's self-sensing capability which will be discussed in the next section. 


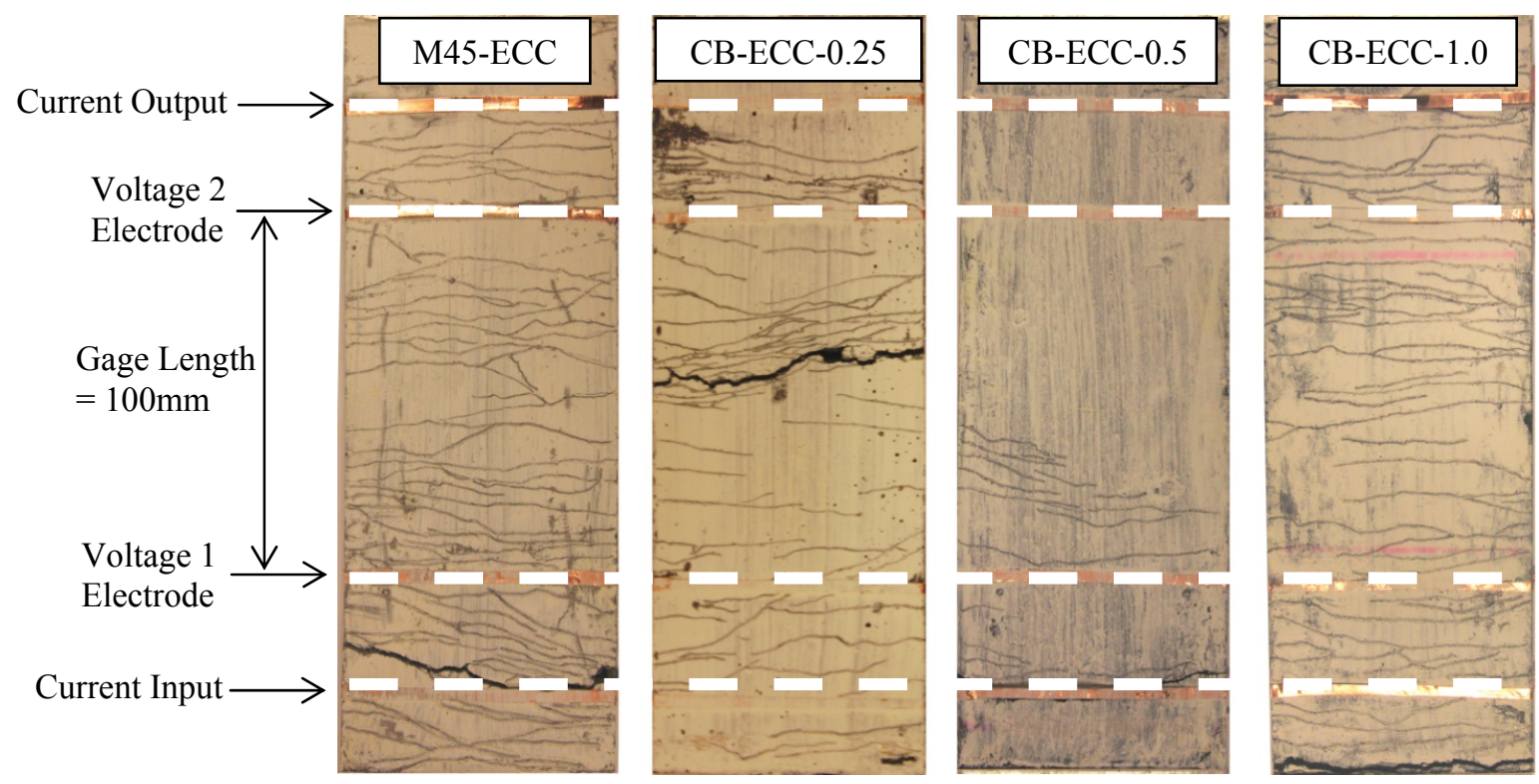

Figure 3. Cracking pattern of M45 and CB-ECC specimens. Note that CB-ECC-0.5 failed prematurely outside the instrumented gage length.

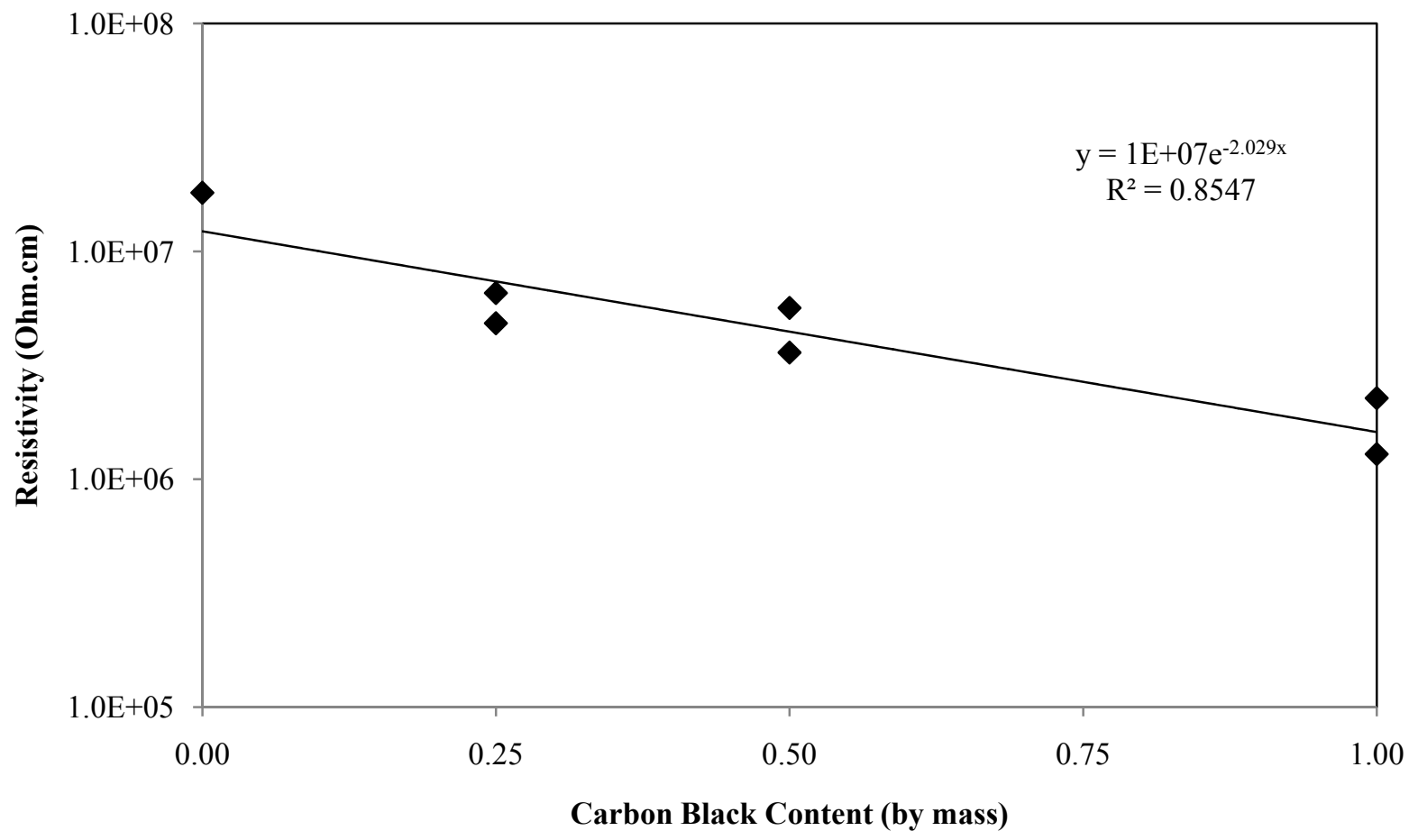

Figure 4. Plot of carbon black content (by mass) versus bulk resistivity (as measured at 1 year). 


\subsection{Tensile-piezoresistive responses}

The resistivity-strain responses of all the specimens, when subjected to uniaxial tension, are shown in Figures 5 through 8. The stress-strain curves were also plotted along with the change in the specimen's resistivity; this is intended to allow for interpretation of changes in resistivity at critical points in the specimen's load history. The gage factors of each specimen in both the elastic and inelastic segment (i.e. strain-hardening) of the load curve were determined and summarized in Table 3. Gage factor is defined as the relative change in resistivity over strain which can be expressed as

$$
\mathrm{GF}=\frac{\Delta R / R}{\varepsilon}
$$

where $\Delta R$ is the change in resistivity, $R$ is the initial resistivity and $\varepsilon$ is the overall strain. As shown in Figures 5 through 8 , all specimens exhibited significant increased resistivity when the specimens were subjected to tension. However, for M45 ECC, after $15000 \mu \varepsilon$, the resistivity decreased instead as the tensile strain increased. This behavior is unusual and is possibly due to the limitation of the test set-up. It should also be noted that the resistivity-strain plot of M45 ECC contains a lot more "noise" after $7000 \mu \varepsilon$ compared to the CB-ECC specimens. This is possibly due to the high initial bulk resistivity of the M45 ECC, coupled with the large increment in resistivity at high strains that may be affecting the accuracy of the Solartron 1260 impedance/gain-phase analyzer. Generally, when subjected to tensile stress/strain, M45 ECC and CB-ECC will first exhibit piezoresistive behavior due to the change in the energy band gap between its valence and conductive band at low strain levels ${ }^{25}$. As the tensile strain increases and the material undergoes strain-hardening, the conductive pathways start to separate or break-down due to the formation of micro-cracks. As these conductive paths break down, the resistivity of the material increases significantly. This is evident as shown in the rate of resistivity change in the material when cracks start to develop (inelastic segment) as compared to the rate of resistivity change during the elastic segment as shown in Figure 9.

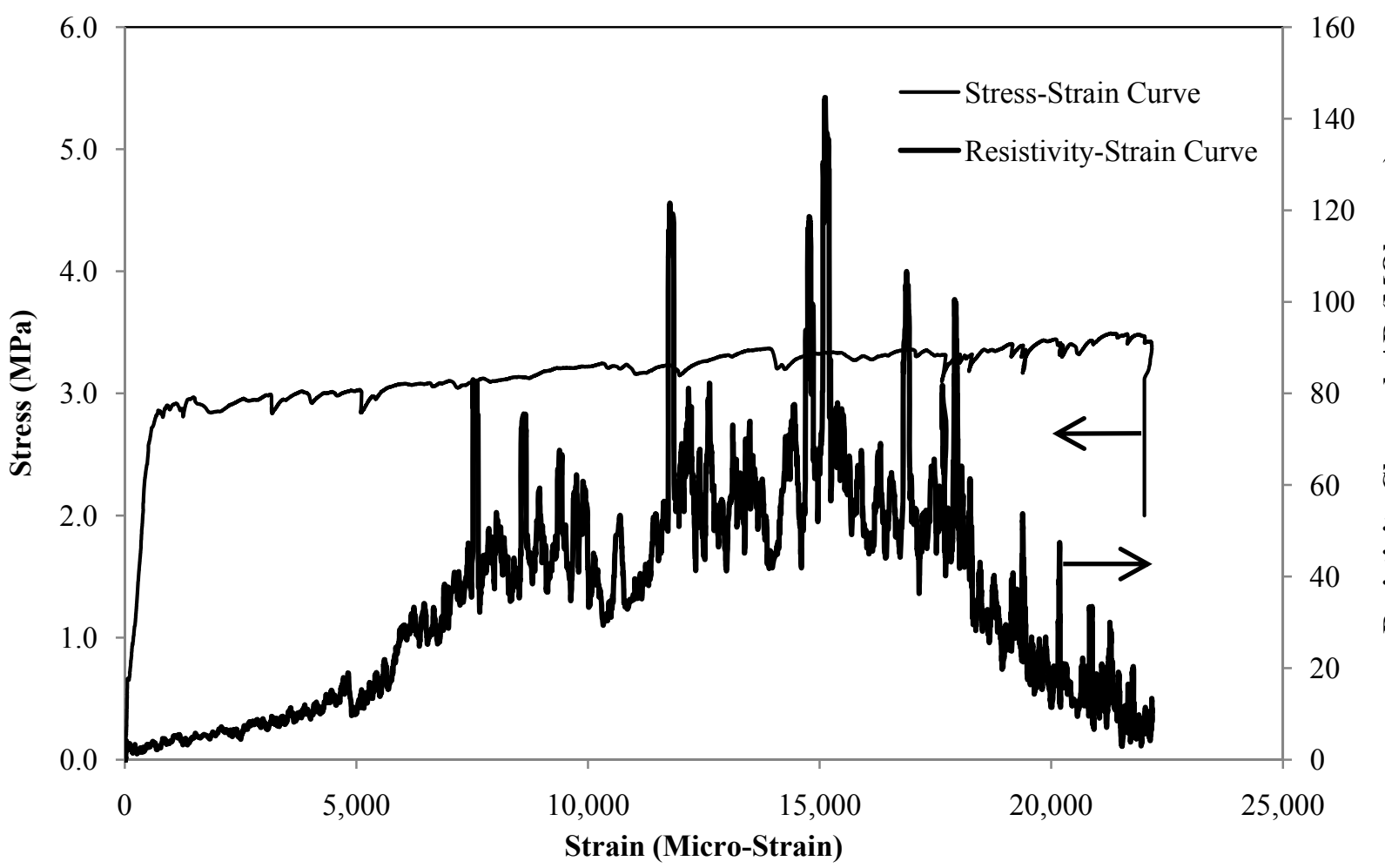

Figure 5. Plot of stress and resistivity changed versus strain of M45-ECC. 


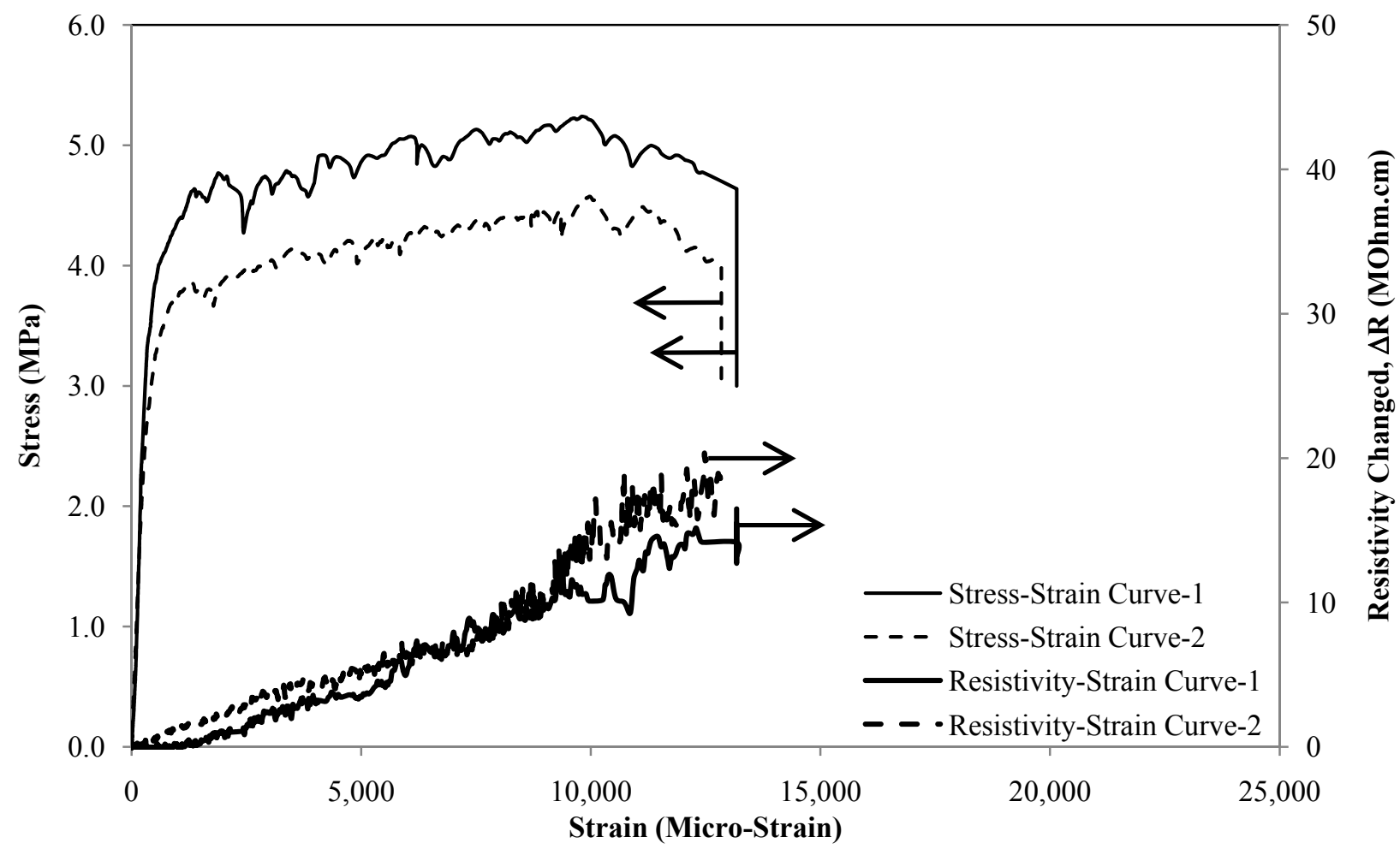

Figure 6. Plot of stress and resistivity changed versus strain of CB-ECC-0.25.

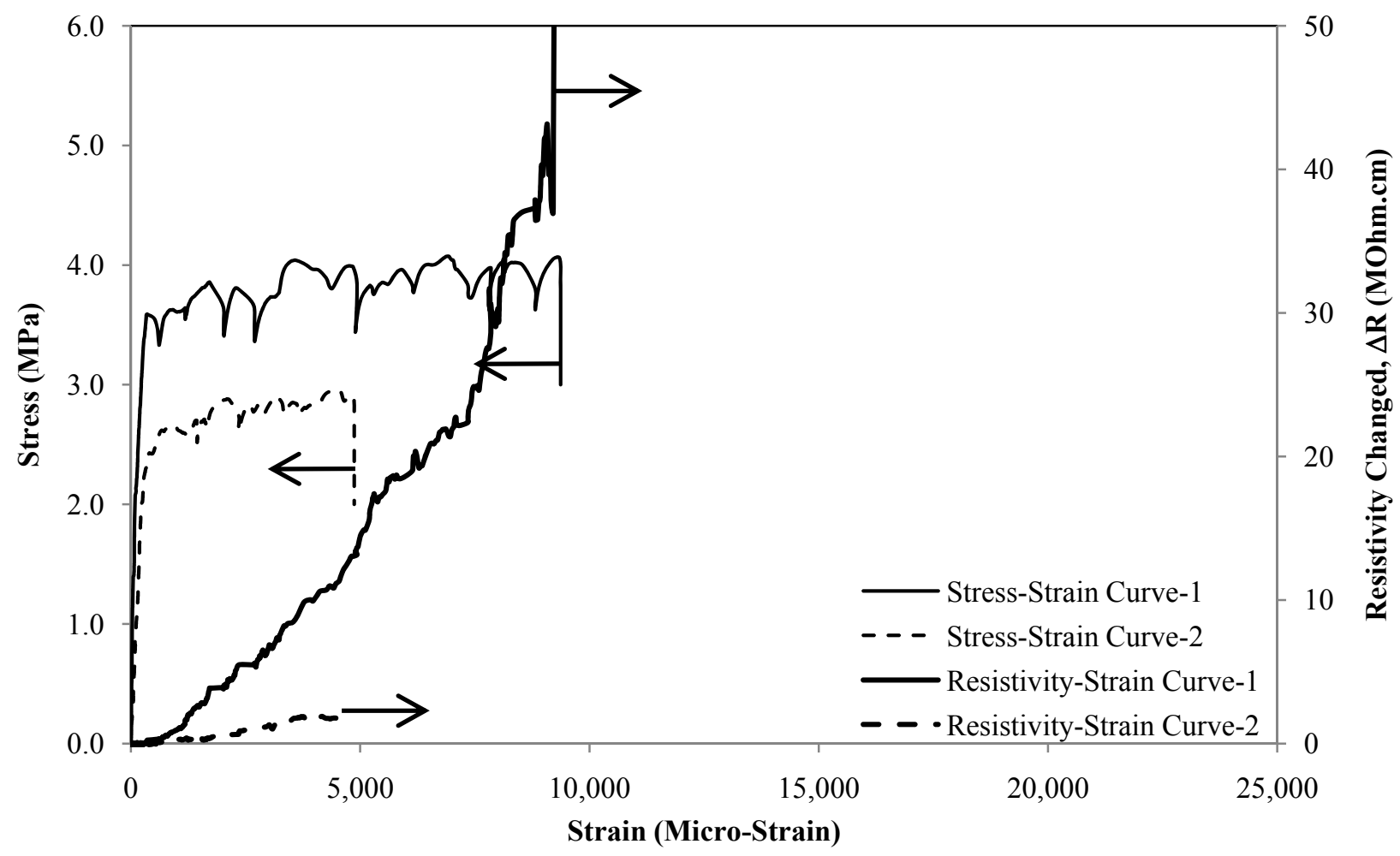

Figure 7. Plot of stress and resistivity changed versus strain of CB-ECC-0.5. 


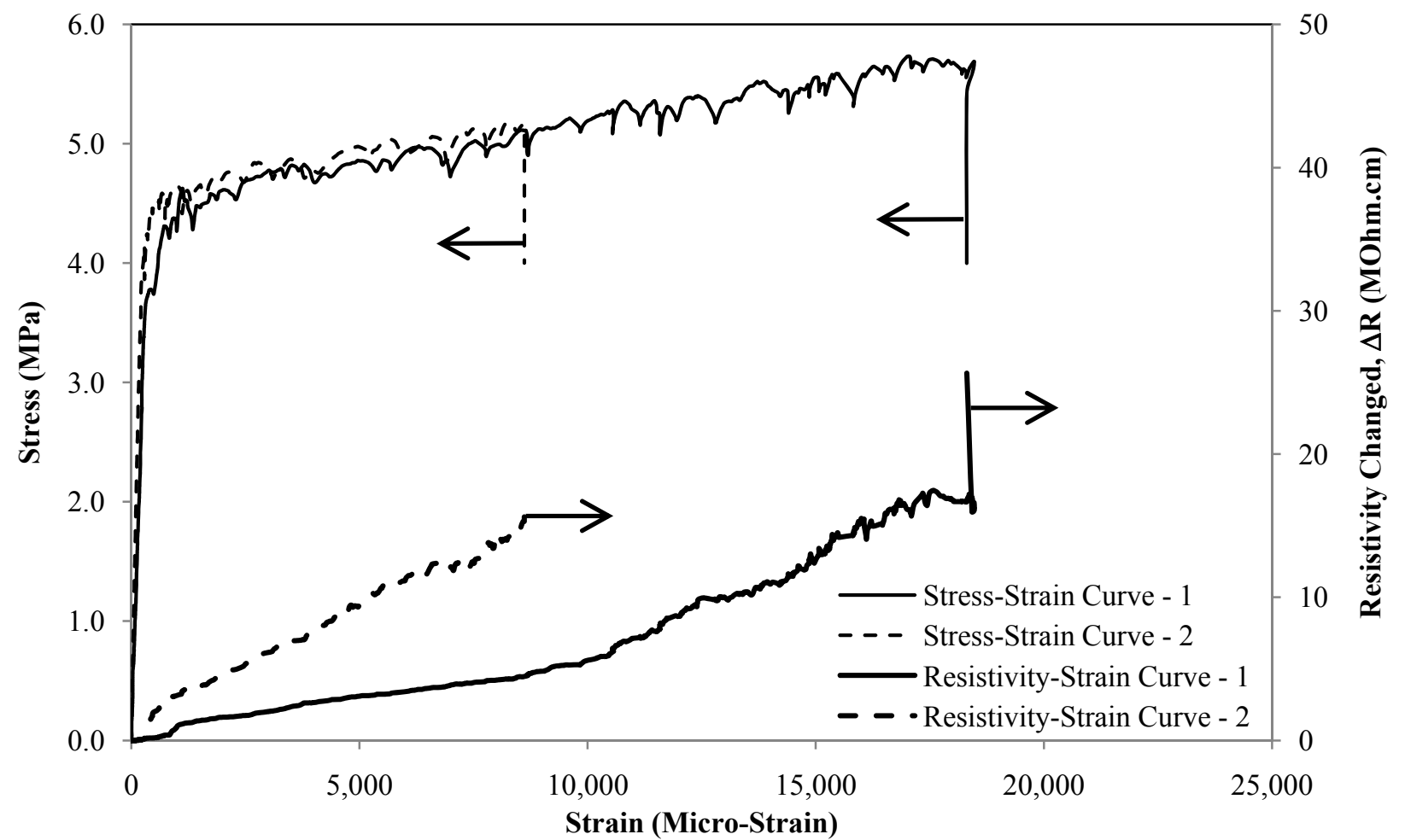

Figure 8. Plot of stress and resistivity changed versus strain of CB-ECC-1.0.

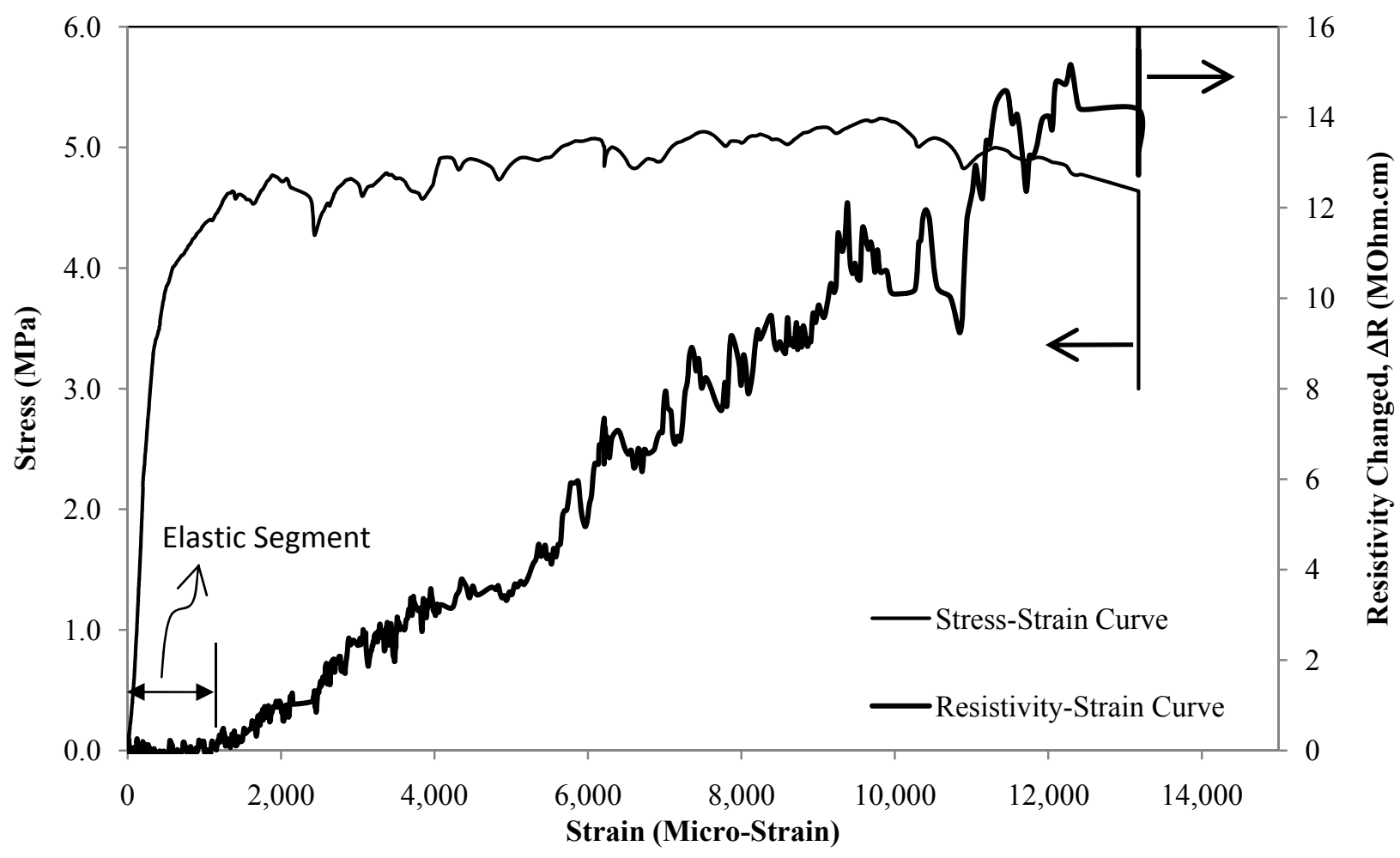

Figure 9. Typical plot of resistivity-strain response (CB-ECC-0.25-1) for illustrating elastic and inelastic segment 
Table 3. Summary of initial resistivity and gage factors.

\begin{tabular}{|l|c|c|c|c|}
\hline Specimen Type & Initial Resistivity (Ohm.cm) & $\begin{array}{c}\text { Elastic Segment } \\
\text { (Gage Factor) }\end{array}$ & $\begin{array}{c}\text { Inelastic Segment } \\
\text { (Gage Factor) }\end{array}$ & Remarks \\
\hline M45 ECC-1 & $1.81 \times 10^{7}$ & 32.2 & 282.7 & $\begin{array}{c}\text { Failed between current and } \\
\text { voltage electrode }\end{array}$ \\
\hline \multirow{2}{*}{ CB-ECC-0.25 } & $6.57 \times 10^{6}$ & 8.7 & 181.9 & Failed within gage length \\
\cline { 2 - 5 } & $4.84 \times 10^{6}$ & 198.1 & 284.3 & Failed within gage length \\
\hline \multirow{2}{*}{ CB-ECC-0.5 } & $5.65 \times 10^{6}$ & 39.6 & 725.5 & $\begin{array}{c}\text { Failed between current and } \\
\text { voltage electrode }\end{array}$ \\
\cline { 2 - 5 } & $3.60 \times 10^{6}$ & 101.3 & 140.0 & $\begin{array}{c}\text { Failed between current and } \\
\text { voltage electrode }\end{array}$ \\
\cline { 2 - 5 } CB-ECC-1.0 & $2.27 \times 10^{6}$ & 67.8 & 706.2 & $\begin{array}{c}\text { Failed between current and } \\
\text { voltage electrode }\end{array}$ \\
\hline
\end{tabular}

From the resistivity-strain plots, the change in resistivity in M45 ECC is significantly higher compared to those of CBECC specimens. At $10000 \mu \varepsilon$, M45 ECC's resistivity increased approximately $60 \mathrm{MOhm} . \mathrm{cm}$ whereas the CB-ECC specimens' resistivity increased from 8 to $40 \mathrm{MOhm} . \mathrm{cm}$. The smaller increases in resistivity of the CB-ECC specimens were likely to be due to the presence of the conductive carbon black particles which were still able to conduct current through the micro-cracks. Conversely, without the carbon black particles, M45 ECC can only rely on the less conductive $\mathrm{C}-\mathrm{S}-\mathrm{H}$ crystals to conduct current through the micro-cracks, leading to larger increases in resistivity during crack formation. Despite the larger increases in resistivity of M45 ECC corresponding to the same strain value, the gage factor of M45 ECC is generally lower than that of CB-ECC due to its high initial resistivity. Therefore, M45 ECC will be less sensitive for self-sensing applications compared to CB-ECC which had higher gage factors.

Observing the stress- and resistivity-strain curves of CB-ECC-1.0, it is interesting to note the disparity in the resistivitystrain curves despite the similarity of the stress-strain curves up to $8000 \mu \varepsilon$. This observation suggests that the piezoresistive behavior of CB-ECC is not only a function of strain, but is also affected by the cracking behavior of the material when subjected to tension.

\section{SUMMARY AND CONCLUSIONS}

From this present study, the uniaxial tensile behavior of CB-ECC with different carbon black content was investigated experimentally. The incorporation of small dosages of carbon black particles into the ECC system was observed to increase the material's first crack and ultimate tensile strength but decrease the tensile strain capacity and average crack width. However, given the limited number of tests carried out, further testing should be conducted to confirm the observations. The piezoresistive behavior of M45 ECC and CB-ECC was also investigated. Significant increase in resistivity was observed when the specimens were subjected to uniaxial tension. The relative increase in resistivity was more pronounced during the inelastic stage due to the multiple cracking process. The gage factors in both the elastic and inelastic segments of the load-curve of M45 ECC and CB-ECC were determined. The incorporation of carbon black particles was shown to be capable of reducing the material's initial bulk resistivity, which is essential for lowering the background resistivity and enhancing the resistivity change in CB-ECC. This preliminary study demonstrated the effectiveness of using carbon black particles to enhance ECC piezoresistive behavior and will serve as a basis for future development of self-sensing CB-ECC. 


\section{ACKNOWLEDGEMENTS}

The authors would like to gratefully acknowledge the U.S. Department of Commerce, National Institute of Standards and Technology (NIST) Technology Innovation Program (TIP) for supporting this research work through Cooperative Agreement Number 70NANB9H9008.

\section{REFERENCES}

[1] Shannag, M. J., "High Strength Concrete Containing Natural Pozzolan and Silica Fume," Cement and Concrete Composites 22(6), 399-406 (2000).

[2] Li, V. C., Wang, S. X. and Wu, C., "Tensile Strain-Hardening Behavior of Polyvinyl Alcohol Engineered Cementitious Composite (PVA-ECC)," ACI Materials Journal 98(6), 483-492 (2001).

[3] Ahmed, S. F. U. and Maalej, M., "Tensile Strain Hardening Behaviour of Hybrid Steel-Polyethylene Fibre Reinforced Cementitious Composites," Construction and Building Materials 23(1), 96-106 (2009)

[4] Li, V. C., "From Micromechanics to Structural Engineering - the Design of Cementitious Composites for Civil Engineering Applications," JSCE Journal of Structural Mechanical Earthquake Engineering 10(2), 37-48 (1993).

[5] Lin, V. W. J., Quek, S. T. and Maalej, M., "Static and Dynamic Tensile Behaviour of PE-Fibrous Ferrocement," Magazine of Concrete Research 63(1), 61-73 (2011).

[6] Ou, J. and Han, B., "Piezoresistive Cement-based Sensors and Self-sensing Concrete Components," Journal of Intelligent Material Systems and Structures 20(3), 329-336 (2009).

[7] Wen, S. and Chung, D. D. L., "Carbon Fiber-Reinforced Cement as a Strain-Sensing Coating," Cement and Concrete Research 31(4), 665-667 (2001).

[8] Wen, S. and Chung, D. D. L., "Electrical-Resistance-Based Damage Self-Sensing in Carbon Fiber Reinforced Cement," Carbon 45(4), 710-716 (2007).

[9] Meehan, D. G., Wang, S. and Chung, D. D. L., "Electrical-resistance-based Sensing of Impact Damage Carbon Fiber Reinforced Cement-based Materials," Journal of Intelligent Material Systems and Structures 21(1), 83-105 (2010).

[10] Shi, Z. Q. and Chung, D. D. L., "Carbon fiber-reinforced concrete for traffic monitoring and weighing in motion," Cement and Concrete Research 29 (3), 435-439 (1999).

[11] Chen, P. and Chung, D. D. L., "Carbon Fiber Reinforced Concrete as a Smart Material Capable of Non-Destructive Flaw Detection," Smart Materials and Structures 2(1), 22-30 (1993).

[12]Chen, P. and Chung, D. D. L., "Improving the Electrical Conductivity of Composites Comprised of Short Conducting Fibers in a Non-Conducting Matrix: the Addition of a Non-Conducting Particulate Filler," Journal of Electronic Materials 24(1), 47-51 (1995).

[13]Fu, X., Lu, W. and Cheung, D. D. L., "Improving the Strain-Sensing Ability of Carbon Fiber-Reinforced Cement by Ozone Treatment of the Fibers," Cement and Concrete Research 28(2), 183-187 (1998).

[14] Wen, S. and Chung, D. D. L., "A Comparative Study of Steel- and Carbon-Fibre Cement as Piezoresistive Strain Sensors," Advances in Cement Research 15(3), 119-128 (2003).

[15] Wen, S. and Chung, D. D. L., "Partial Replacement of Carbon Fiber by Carbon Black in Multifunctional CementMatrix Composites," Carbon 45(3), 505-513 (2007).

[16] Wen, S. and Chung, D. D. L., "Uniaxial Tension in Carbon Fiber Reinforced Cement, Sensed by Electrical Resistivity Measurements in Longitudinal and Transverse Directions," Cement and Concrete Research 30(8), 12891294 (2000).

[17] Wen, S. and Chung, D. D. L., "Uniaxial Compression in Carbon Fiber Reinforced Cement, Sensed by Electrical Resistivity Measurements in Longitudinal and Transverse Directions," Cement and Concrete Research 31(2), 297 301 (2001).

[18] Reza, F., Batson, G. B., Yamamuro, J. A. and Lee, J. S., "Resistance Changes during Compression of Carbon Fiber Cement Composites," Journal of Materials in Civil Engineering 15(5), 476-483 (2003).

[19] Wen, S. and Chung, D. D. L., "Self-Sensing of Flexural Damage and Strain in Carbon Fiber Reinforced Cement and Effect of Embedded Steel Reinforcing Bars," Carbon 44(8), 1496-1502 (2006).

[20] Fu, X. and Chung, D. D. L., "Effect of Curing Age on the Self-Monitoring of Carbon Fiber Reinforced Mortar," Cement and Concrete Research 27(9), 1313-1318 (1997). 
[21]Han, B., Yu, X. and Ou, J., "Effect of Water Content on the Piezoresistivity of MWNT/Cement Composites," Journal of Materials Science 45(14), 3714-3719 (2010).

[22] Han, B., Zhang, L. and Ou, J., "Influence of Water Content on Conductivity and Piezoresistivity of Cement-Based Material with both Carbon Fiber and Carbon Black," Journal of Wuhan University of Technology-Materials Science Edition 25(1), 147-151 (2010).

[23] Li, V. C. and Leung, C. K. Y., "Steady-State and Multiple Cracking of Short Random Fiber Composites," Journal of Engineering Mechanics 118(11), 2246-2264 (1992).

[24]Li, V. C. and Wu, H. C., "Pseudo Strain-Hardening Design in Cementitious Composites," High Performance Fiber Reinforced Cementitious Composites, edited by Reinhardt, H. W. and Naaman, A. E., Chapman \& Hall, London, 371-387 (1992).

[25] Smith, C. S., "Piezoresistance Effect in Germanium and Silicon," Physical Review 94(1), $42-49$ (1956). 